\title{
Exosome-shuttling microRNA-21 promotes cell migration and invasion-targeting PDCD4 in esophageal cancer
}

\author{
JUAN LIAO, RAN LIU, YA-JUAN SHI, LI-HONG YIN and YUE-PU PU \\ Key Laboratory of Environmental Medicine Engineering, Ministry of Education, \\ School of Public Health, Southeast University, Nanjing, Jiangsu 210009. P.R. China
}

Received February 2, 2016; Accepted March 7, 2016

DOI: 10.3892/ijo.2016.3453

\begin{abstract}
Recent evidence indicates that exosomes can mediate certain microRNAs (miRNAs) involved in a series of biological functions in tumor occurrence and development. Our previous studies showed that microRNA-21 (miR-21) was abundant in both esophageal cancer cells and their corresponding exosomes. The present study explored the function of exosome-shuttling miR-21 involved in esophageal cancer progression. We found that exosomes could be internalized from the extracellular space to the cytoplasm. The exosomederived Cy3-labeled miR-21 mimics could be transported into recipient cells in a neutral sphingomyelinase 2 (nSMase2)dependent manner. miR-21 overexpression from donor cells significantly promoted the migration and invasion of recipient cells by targeting programmed cell death 4 (PDCD4) and activating its downstream c-Jun N-terminal kinase (JNK) signaling pathway after co-cultivation. Our population plasma sample analysis indicated that miR-21 was upregulated significantly in plasma from esophageal cancer patients and showed a significant risk association for esophageal cancer. Our data demonstrated that a close correlation existed between exosome-shuttling miR-21 and esophageal cancer recurrence and distant metastasis. Thus, exosome-shuttling miR-21 may become a potential biomarker for prognosis among esophageal cancer patients.
\end{abstract}

\section{Introduction}

Esophageal squamous cell carcinoma (ESCC) is one of the most common malignant tumors worldwide and seriously threatens human health (1). As current methods for ESCC

Correspondence to: Professor Ran Liu or Professor Li-Hong Yin, Key Laboratory of Environmental Medicine Engineering, Ministry of Education, School of Public Health, Southeast University, No. 87 Dingjiaqiao Street, Nanjing, Jiangsu 210009, P.R. China

E-mail: ranliu@seu.edu.cn

E-mail: lhyin@seu.edu.cn

Key words: cell-cell communication, exosome, miR-21, esophageal cancer screening are invasive and can hardly detect ESCC in its early stages, clinically significant and minimally invasive tests for ESCC are necessary. Recently, the potential applications of circulating tumor cell-associated microRNAs have been investigated, and these miRNAs have been suggested as novel biomarkers in plasma or serum for cancer diagnosis (2-6). A series of miRNA expression profile studies in plasma from cancer patients has been conducted to explore the tumorspecific miRNAs. A research on pancreatic cancer (PC) found 37 miRNAs downregulated and 54 miRNAs upregulated in plasma from patients with PC. Furthermore, miR-21 was correlated with worse PC survival, whereas let-7 was inversely correlated with survival (7). With the current development of next-generation deep sequencing, Illumina platform-based sequencing was performed to establish a plasma miRNA profile in nasopharyngeal carcinoma (NPC) patients; 13 miRNAs were found to be NPC specific (8). miRNAs may be widely used as a clinical biomarker as miRNAs in plasma were demonstrated to be resistant to ribonuclease digestion and temperature changes $(9,10)$.

Exosomes, which are small vesicles of endocytic origin, were reported to be released with miRNAs wrapped from both tumor and healthy cells to participate in cell-cell communication (11-13). Rabinowits et al (14) evaluated the expression level of 12 miRNAs from lung adenocarcinoma tissues and circulating exosomes vs. the control group; their study found that the tumor-derived miRNA patterns and the circulating exosomal miRNAs were similar. Taylor et al (15) detected a greater number of circulating epithelial cell adhesion molecule (EpCAM)-positive exosomes in ovarian cancer patients than benign ovarian disease or controls. They also discovered that there existed a similar level of miRNA profile between ovarian cancer cells and exosomes, which suggest that tumor-derived exosomal miRNA profiling could be used as a diagnosis approach. Therefore, circulating miRNA profiles of exosomes may be applied in tumor early diagnosis, prognosis and recurrence with a great value.

Current research has indicated that the transfer of exosomederived miRNAs to recipient cells is a novel mechanism in addition to classical mechanisms, which include direct cell-cell contact or chemical receptor-mediated events (16). The number of studies that deal with identification of exosomal miRNA function is increasing in recent years. Tumor cell-derived exosome-formed miRNAs have been shown to be transferred 
into recipient cells and performed their biological functions. Nouraee et al (17) demonstrated that miR-21 could be detected in conditioned media of esophageal cancer cells. Moreover, a significant miR-21 upregulation in esophageal cancer cells was observed when these cells were co-cultured with fibroblasts; this process provided the possibility for transfer of exosome-shuttling miRNAs. Some researchers have found that co-culture with exosomes derived from miR-10b vector stable transfected-breast cancer cells could induce breast epithelial cell invasiveness; thus, exosome-shuttling miRNAs may play an important role in tumor microenvironment modulation (18). A study on co-cultivation of leukemia cells and endothelial cells revealed that exogenous miR-92a could enhance recipient endothelial cell migration and tube formation, such as endogenous miR-92a, via exosomal transport by targeting its target gene, namely, integrin $5 \alpha$ (19). An increase in evidence raises the possibility that genetic information can be transferred via exosomes between cells. Thus, we hypothesized that exosomeshuttling miRNAs can be transferred between esophageal cells. Furthermore, certain miRNAs may contribute to the change of biological properties by affecting their target genes in recipient cells.

In our previous studies, the expression profiling of exosomal miRNAs was derived from esophageal cancer cells through high-throughput sequencing (20); basing on the said study, we have revealed that miR-21 was abundant both in esophageal cancer cells and their corresponding exosomes. However, no studies have reported on the functional research of exosomeshuttling miR-21 in esophageal cancer. In the present study, we explored the exosome-shuttling miR-21 involved in esophageal cancer progression by analyzing its impact on esophageal cancer migration and invasion. In addition, we investigated the regulatory mechanism behind this gene, including the target gene and downstream molecules. Case-control study was also conducted to identify the association of exosome-shuttling miR-21 and esophageal cancer risk.

\section{Materials and methods}

Specimen collection and ethics statement. Seventy patients, aged 47 to 82 years, were recruited from the First People's Hospital of Huaian, with their consent and agreement. All patients were confirmed by pathology or endoscopy as ESCC without preoperative radiotherapy or chemotherapy. Plasma samples were also collected from 70 healthy volunteers, aged between 46-84 years, with matching age and gender to the patients. Among these patients, blood plasma samples from three ESCC female patients, aged 58, 73 and 77, and three female healthy volunteers, aged 60, 76 and 80, were selected for miRNA microarray analysis. Written consents were obtained from all subjects prior to recruitment. The study protocol was approved by the Institutional Review board (IRB) of Southeast University Affiliated Zhongda Hospital in Nanjing, China. The design of the esophageal cancer study, including plasma sample collection, was approved by the IRB.

miRNA microarray. Three pairs of plasma samples from ESCC patients and healthy controls were collected for microarray analysis. Agilent Human miRNA microarray (v19.0;
Agilent Technologies Inc., Santa Clara, CA, USA) was used in the analysis. miRNA samples from six esophageal specimens were labeled and hybridized with miRNA Complete Labeling and Hybridization kit (Agilent Technologies) according to the manufacturer's protocol. Signals were normalized using Gene Spring software 11.0 (Agilent Technologies). ANOVA was used to compare the different miRNA expressions.

Cell culture. The human esophageal cancer cell line EC9706 (National Laboratory of Molecular Oncology, Cancer Institute, Chinese Academy of Medical Sciences and Peking Union Medical College, Beijing, China) (21) was maintained in RPMI-1640 medium that contains $10 \%$ fetal bovine serum (FBS), $100 \mathrm{U} / \mathrm{ml}$ penicillin and $100 \mu \mathrm{g} / \mathrm{ml}$ streptomycin. FBS was centrifuged $10,000 \mathrm{x}$ g for $30 \mathrm{~min}$, followed by ultracentrifugation at 200,000 $\mathrm{xg}$ for $6 \mathrm{~h}$ to eliminate bovine-derived exosomes using a Type 70 Ti rotor in L-80XP ultracentrifuge (Beckman Coulter, Brea, CA, USA) (22). Cell cultures were performed at $37^{\circ} \mathrm{C}$ in a $5 \% \mathrm{CO}_{2}$, water-saturated atmosphere.

Exosome purification. Culture medium from EC9706 (1x10 ${ }^{8}$ cells) was collected after a 48 -h culture; this medium was subjected to differential centrifugation. Briefly, the medium was first centrifuged at $300 \mathrm{x} \mathrm{g}$ for $10 \mathrm{~min}, 800 \mathrm{x} \mathrm{g}$ for $10 \mathrm{~min}, 1,200 \mathrm{x} \mathrm{g}$ for $20 \mathrm{~min}$, and $10,000 \mathrm{x} \mathrm{g}$ for $30 \mathrm{~min}$ to remove any live or dead cells and cellular debris. Afterwards, the supernatant was ultracentrifuged at $100,000 \times \mathrm{g}$ for $3 \mathrm{~h}$ to pellet exosomes. The supernatant was disposed, and the exosome pellet was washed with phosphate-buffered saline (PBS) at 100,000 x g for $2 \mathrm{~h}$. All steps were performed at $4^{\circ} \mathrm{C}$. The pellet was finally re-suspended in the appropriate buffer for future studies. The exosome levels were determined by measuring the total protein content, which was presented as micrograms of total protein in the exosomes. The exosome fraction was measured for its protein content using a Pierce BCA protein assay kit (Thermo Fisher Scientific, Wilmington, DE, USA).

Exosome labeling and live-cell fluorescence microscopy. The exosome pellet suspension was diluted to a $40 \mu \mathrm{g} / \mathrm{ml}$ concentration with RPMI-1640 medium by adding $5 \mu \mathrm{g} / \mathrm{ml}$ DiI (Biotium, Hayward, CA, USA), which is a fluorescent dye that labels the plasma membrane. This suspension was then incubated at $37^{\circ} \mathrm{C}$ for $30 \mathrm{~min}$ and subsequently passed through a $0.22-\mu \mathrm{M}$ filter to remove bacteria. The excessive dye was removed using a 300-kDa ultrafiltration tube (Pall Corp., Washington, NY, USA) five times at $4000 \mathrm{x} \mathrm{g}$ for $10 \mathrm{~min}$ centrifugation. For Live Cell Imaging System analysis, $2 \times 10^{5}$ EC9706 and $1.5 \mathrm{ml}$ complete medium (RPMI-1640 with 10\% FBS) were placed in a 35-mm glass-bottom culture dish (Nest Biotechnology Co., Ltd., Wuxi, China). After a 24-h culture, the DiI-labeled exosomes were incubated with cells for $2.5 \mathrm{~h}$ and washed once to eliminate the free exosomes. Cells were then transferred to the cell culture chamber of the microscope, which could provide temperature and $\mathrm{CO}_{2}$ concentration that can sustain live cells. Fluorescence emission was collected by x60 oil-immersion objective and passed through EM 565-nm emission filters. Fluorescence images could be recorded at $0.6 \mathrm{ftp}$ speed using the UltraVIEW VoX Live Cell Imaging System (Perkin-Elmer, Waltham, MA, USA). 
Co-cultivation experiment. Co-cultivation of EC9706 cells was performed in 12-well Transwell inserts (cat. no. 3401; Corning Inc., Corning, NY, USA). EC9706 cells that were treated as recipient cells were pre-seeded in the lower chambers at a $1 \times 10^{5}$ cells/well density. The following day, the EC9706 cells transfected with miR-21 mimics or the negative controls that were treated as donor cells were scraped off and seeded onto $0.4 \mu \mathrm{M}$ Transwell inserts, which were filtered to supernatants but not to the cellular components (23).

Inhibition of exosome release. To validate whether miR-21 secretion depends on exosome transfer, exosome release was blocked using GW4869 (sc-218578; Santa Cruz Biotechnology, Santa Cruz, CA, USA), which is a specific chemical inhibitor for nSMase2. EC9706 cells were pre-seeded in a 24-well plate and cultured for $12 \mathrm{~h}$ in complete medium. After the incubation, the medium was switched to fresh complete medium with different GW4869 concentrations. The cells were collected, and exosome fraction was obtained from the culture medium after 48-h incubation.

Transfer efficiency assay for Cy3-labeled miR-21 mimics. EC9706 cells $\left(3.5 \times 10^{5} /\right.$ well) treated as donor cells were transfected with $30 \mathrm{nM}$ of Cy3-labeled miR-21 mimics using Lipofectamine RNAiMAX (Invitrogen). One day after 12-h transfection, the culture medium was disposed, and cells were washed thrice with PBS to remove the residual transfection reagent. Subsequently, the medium was changed to fresh complete medium. Culture medium from donor cells was collected and centrifuged to remove residual cells after a 24-h culture. These cells were then added into pre-seeded recipient EC9706 cells ( $2 \times 10^{5} /$ well) in a 6-well plate. The recipient cells were acquired after 3, 6 and 24 h of culture. Transfer efficiency was calculated as fluorescent cell percentage by flow cytometry. The miR-21 expression level in recipient cells was detected by real-time quantitative polymerase chain reaction (RT-qPCR).

RNA extraction and quantitative reverse transcription PCR. Total RNA was extracted from cells and exosomes using TRIzol reagent (Invitrogen) and mirVana miRNA isolation kit (Ambion, Austin, TX, USA) according to the manufacturer's instructions, respectively. RNA concentration was analyzed using NanoDrop spectrophotometer (NanoDrop ND-1000; NanoDrop Technologies, Inc., Wilmington, DE, USA). RT-qPCR was performed using SYBR-Green Master Mix Plus (Toyobo, Osaka, Japan). Real-time PCR was performed in 96-well plates using Primer Express software version 3.0 (Applied Biosystems, Foster City, CA, USA). RNU6 and cel-miR-39 were used as the invariant control for cells and supernatant, respectively, in miR-21 expression level analysis. $\beta$-actin was used as the invariant control for mRNA analysis. The sequences of PDCD4 primers were as follows: forward, 5'-TATGATGTGGAGGAGGTGGATGTGA-3' and reverse, 5'-CCTTTCATCCAAAGGCAAAACTACAC-3'. The sequences of matrix metalloproteinases (MMP)-2 primers were as follows: forward, 5'-CTGATGGCACCCATTTACA CCT-3' and reverse, 5'-GATCTGAGCGATGCCATCAAA-3'. The sequences of MMP-9 primers were as follows: forward, 5'-TGGGCTACGTGACCTATGACAT-3' and reverse, 5'-GCC
CAGCCCACCTCCACTCCTC-3'. The sequences of $\beta$-actin primers were as follows: forward, 5'-ATCCGCAAAGACC TGT-3' and reverse, 5'-GGGTGTAACGCAACTAAG-3'. The primers used for the amplification of miR-21, RNU6 and cel-miR-39 were purchased from Guangzhou RiboBio Co., Ltd. (Guangzhou, China). The PCR reaction was performed at $95^{\circ} \mathrm{C}$ for $5 \mathrm{~min}$, which was followed by 40 cycles of $95^{\circ} \mathrm{C}$ for $15 \mathrm{sec}, 60^{\circ} \mathrm{C}$ for $30 \mathrm{sec}$, and $72^{\circ} \mathrm{C}$ for $30 \mathrm{sec}$. Dissociation curve was analyzed from 60 to $99^{\circ} \mathrm{C}$. Relative transcript quantities for each miRNA were calculated using the $\Delta \Delta \mathrm{Ct}$ method.

Cell migration assay. Transwell migration assay was performed using a Transwell insert that contains a polycarbonate filter with $8 \mu \mathrm{M}$ pore size (cat. no. 3422; Corning). Transfected recipient cells $\left(5 \times 10^{3}\right)$ suspended in $150 \mu 1$ serumfree RPMI-1640 were added to the 24-well upper chamber. The chambers were placed in 24-well plates, and $600 \mu 1$ RPMI-1640 that contains 10\% FBS was added to the bottom wells of the multiwell insert assembly. Cells were incubated at $37^{\circ} \mathrm{C}$ for $12 \mathrm{~h}$ to allow cell migration through the membrane. Migrated cells were fixed in $95 \%$ ethanol and stained with crystal violet. Migrated cell images were captured by FSX100 (Olympus) at x200 magnification. Cell migration was quantitated by counting in 10 random fields on the lower membrane surface.

Cell invasion assay. Invasiveness of donor and recipient cells from the co-culture model was measured by cell invasion through a Matrigel (BD Biosciences)-coated Transwell inserts with $8 \mu \mathrm{M}$ pore size (cat. no. 3422; Corning). Approximately $150 \mu \mathrm{l}$ cell suspension ( $1 \times 10^{5}$ cells) in serum-free RPMI-1640 was added into the upper well of the chamber in triplicate wells, whereas the lower wells were filled to the top $(\sim 600 \mu \mathrm{l})$ with RPMI-1640 that contains 50\% FBS. After 12-h incubation, the non-invasive cells were removed with a cotton swab, and MTT stock solution was added to each culture to obtain a final MTT concentration of $0.5 \mathrm{mg} / \mathrm{ml}$ in the medium. Afterwards, the inserts with adherent cells on the lower membrane surface were incubated for $4 \mathrm{~h}$ at $37^{\circ} \mathrm{C}$. Subsequently, $500 \mu 1100 \%$ DMSO was added to solubilize the MTT-formazan product per well. After thorough mixing, the absorbance was measured with a microplate reader at a $490 \mathrm{~nm}$ test wavelength.

Luciferase reporter assay. The 3'-UTR segment of PDCD4 mRNA, which contains the miR-21-binding sites, was amplified by PCR from human genomic DNA. Subsequently, this segment was cloned into the pmiR-RB-Report plasmid (Guangzhou RiboBio), which encodes two luciferase reporter genes to obtain the wild-type plasmid pmiR-Report-WTPDCD4. Mutant-type plasmids pmiR-Report-MUT-PDCD4 were generated by changing the binding site for miR-21 'AUAAGCU' to 'UAUUGCA' from the corresponding wildtype pmiR-RB-Report plasmid. EC9706 cells in the miR-21 mimics or negative control group were transfected in 96-well plates $\left(1 \times 10^{4}\right.$ cells/well) with pmiR-Report-WT-PDCD4 as well as the corresponding mutant reporter plasmid by Lipofectamine RNAiMAX. The Renilla luciferase was used as an internal control. Luciferase activity was measured using the Dual-Luciferase reporter assay system (Promega) $48 \mathrm{~h}$ after transfection. 


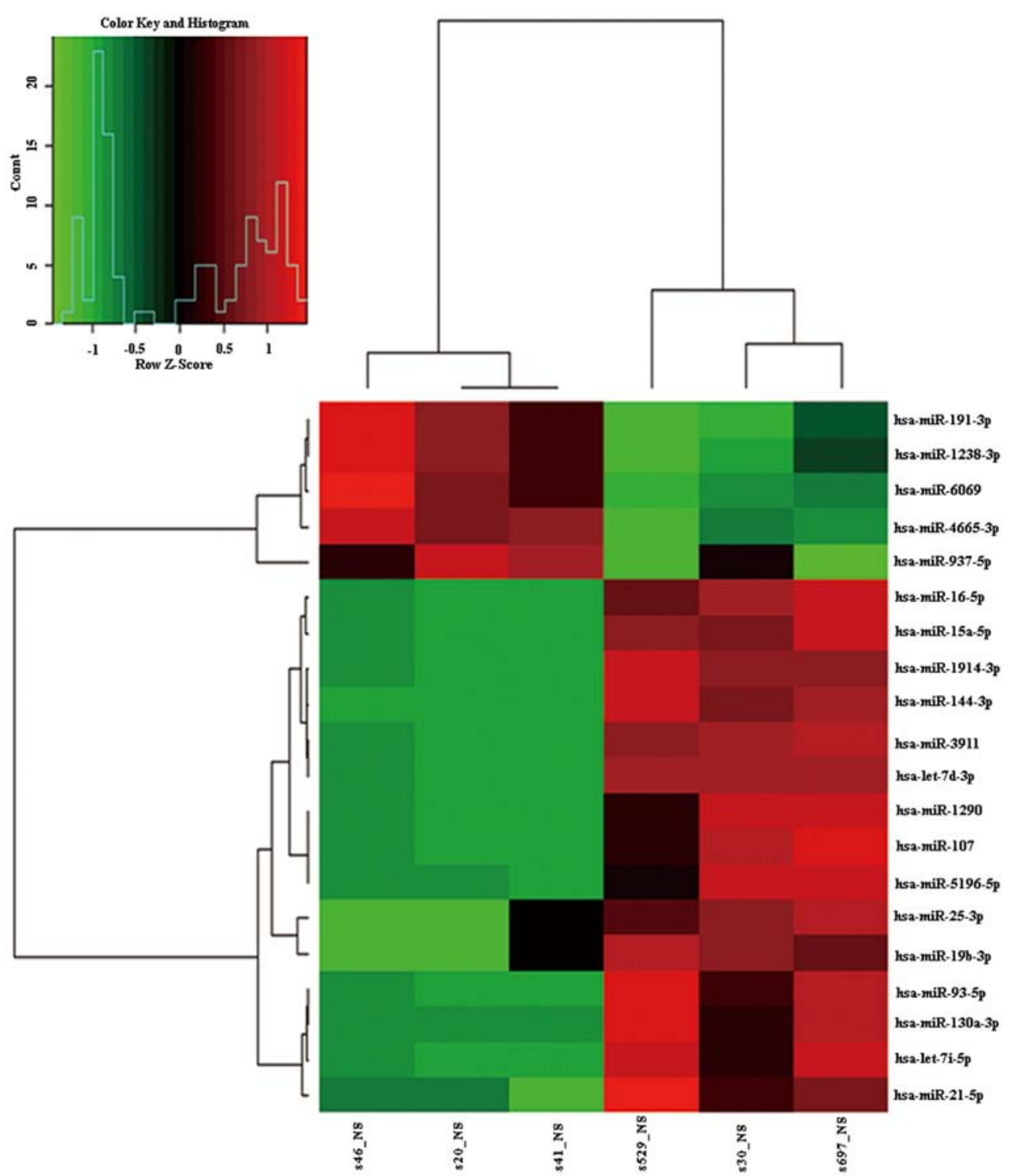

Figure 1. Cluster analysis of differentially expressed miRNAs in plasma from ESCC patients vs. healthy controls. The result of hierarchical clustering shows a distinguishable gene expression profiling between samples. The rows show 20 differentially expressed miRNAs, whereas the columns show 3 paired samples. Red represents high expression, whereas green represents low expression.

Immunoblot analysis. For western blot analysis, miR-21 mimic/ negative control-transfected EC9706 cells were lysed with RIPA lysis buffer and protease inhibitors (Beyotime Institute of Biotechnology, Haimen, China) at $14,000 \mathrm{x} g$ for $5 \mathrm{~min}$ at $4^{\circ} \mathrm{C}$. A total of $20 \mu \mathrm{g}$ protein was separated on $10 \%$ SDS-PAGE gels and transferred to PVDF membranes $(0.45 \mu \mathrm{M}$ pore size; Millipore, Billerica, MA, USA). Membranes were blocked with non-fat milk and incubated with primary antibodies anti-PDCD4 (1:1,000) (no. 9535S; Cell Signaling Technology, Danvers, MA, USA), MMP-2 (1:500) (ab7033; Abcam, Cambridge, UK), MMP-9 (1:500) (MAB3309; Millipore), and $\beta$-actin (1:1000) (BM0627; Wuhan Boster Biological Technology, Ltd., Wuhan, China) overnight at $4^{\circ} \mathrm{C}$. Primary antibody incubation was followed by incubation with horseradish peroxidase-conjugated secondary antibodies for $1 \mathrm{~h}$ at room temperature. The protein-antibody complex was visualized using the enhanced chemiluminescence kit (Thermo Fisher Scientific) and chemiluminescence image analysis system (Tanon 5200; Tanon Science, Shanghai, China).

\section{Results}

Candidate miRNA screening by microarray. The microarray data of plasma from esophageal cancer patients and healthy control have been submitted to GEO website with accession number GSE71043. Microarray analysis identified 20 miRNAs that could distinguish the plasma from ESCC patients and healthy controls. A total of $15 \mathrm{miRNAs}$ were found to be overexpressed in plasma from ESCC patients (hsa-miR-16-5p, hsa-miR-130a-3p, hsa-miR-15a-5p, hsa-miR-144-3p, hsa-miR-19b-3p, hsa-miR-5196-5p, hsa-miR-25a-3p, hsa-miR-1914-3p, hsa-miR-93-5p, hsa-miR-107, hsa-miR-3911, hsa-miR-21-5p, hsa-let-7d-3p, hsa-let7i-5p and hsa-miR-1290). By contrast, hsa-miR-1238-3p, hsa-miR-6069, hsa-miR191-3p, hsa-miR-4665-3p and hsa-miR-937-5p were found to be downregulated (Table I). Cluster analysis, based on the differentially expressed miRNAs, successfully separated the plasma samples from ESCC patients and healthy controls (Fig. 1). 

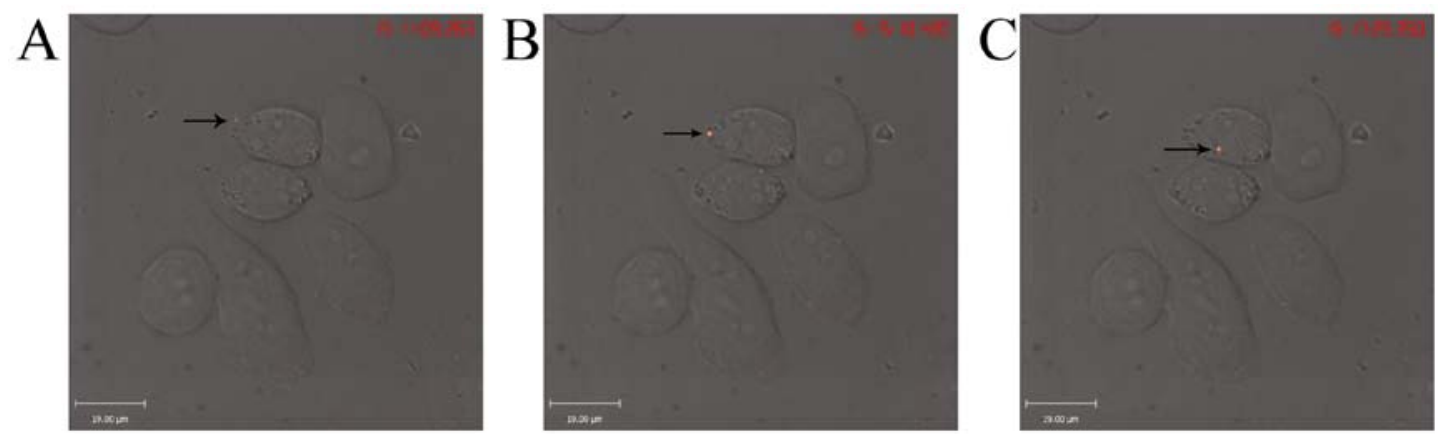

Figure 2. Internalized process of DiI-labeled exosomes from extracellular cells to cytoplasm. The time interval image of DiI-exosomes (black arrow) in (A) the extracellular environment, (B) on the cell membrane, and (C) in the intercellular environment was screenshot from the video.

Table I. Differential expression of miRNAs in plasma from ESCC patients (g1) vs. healthy controls (g2) by microarray.

\begin{tabular}{lccl}
\hline $\begin{array}{l}\text { Systematic } \\
\text { name of } \\
\text { miRNA }\end{array}$ & $\begin{array}{c}\text { P-value } \\
(<0.05)\end{array}$ & $\begin{array}{c}\text { Fold change } \\
(\mathrm{g} 1 / \mathrm{g} 2)\end{array}$ & $\begin{array}{l}\text { Expression level } \\
\text { of g1 compared } \\
\text { with g2 }\end{array}$ \\
\hline hsa-let-7d-3p & 0.000632 & 3.55 & Upregulation \\
hsa-let-7i-5p & 0.028094 & 3.484 & Upregulation \\
hsa-miR-107 & 0.038254 & 9.687 & Upregulation \\
hsa-miR-1238-3p & 0.026845 & 0.112 & Downregulation \\
hsa-miR-1290 & 0.029073 & 3.307 & Upregulation \\
hsa-miR-130a-3p & 0.049716 & 104.736 & Upregulation \\
hsa-miR-144-3p & 0.008005 & 36.17 & Upregulation \\
hsa-miR-15a-5p & 0.014182 & 38.202 & Upregulation \\
hsa-miR-16-5p & 0.016302 & 111.321 & Upregulation \\
hsa-miR-191-3p & 0.029836 & 0.166 & Downregulation \\
hsa-miR-1914-3p & 0.01045 & 10.139 & Upregulation \\
hsa-miR-19b-3p & 0.030333 & 13.434 & Upregulation \\
hsa-miR-21-5p & 0.046401 & 6.779 & Upregulation \\
hsa-miR-25-3p & 0.038363 & 11.525 & Upregulation \\
hsa-miR-3911 & 0.000374 & 8.137 & Upregulation \\
hsa-miR-4665-3p & 0.005431 & 0.263 & Downregulation \\
hsa-miR-5196-5p & 0.037794 & 11.583 & Upregulation \\
hsa-miR-6069 & 0.042763 & 0.136 & Downregulation \\
hsa-miR-93-5p & 0.028228 & 9.745 & Upregulation \\
hsa-miR-937-5p & 0.048971 & 0.319 & Downregulation \\
& & &
\end{tabular}

Movement trail of EC9706 cell-derived exosomes. To examine whether exosomes derived from EC9706 cells can be accepted by recipient cells, we labeled exosomes with DiI dye (red fluorescence) as described in Materials and methods. When DiI-labeled exosomes were added to the culture medium, red fluorescence was traced in recipient EC9706 cells using live-cell fluorescence microscopy. The exosome sizes were below diffraction limit; thus, DiI-labeled exosomes on glass were represented as small dots in wide-field fluorescence images (24). We observed an internalization of DiI-labeled exosomes from the extracellular environment to the cytoplasm of recipient EC9706 cells (Fig. 2). These studies indicated that EC9706 cell-derived exosomes could be accepted by recipient cells.
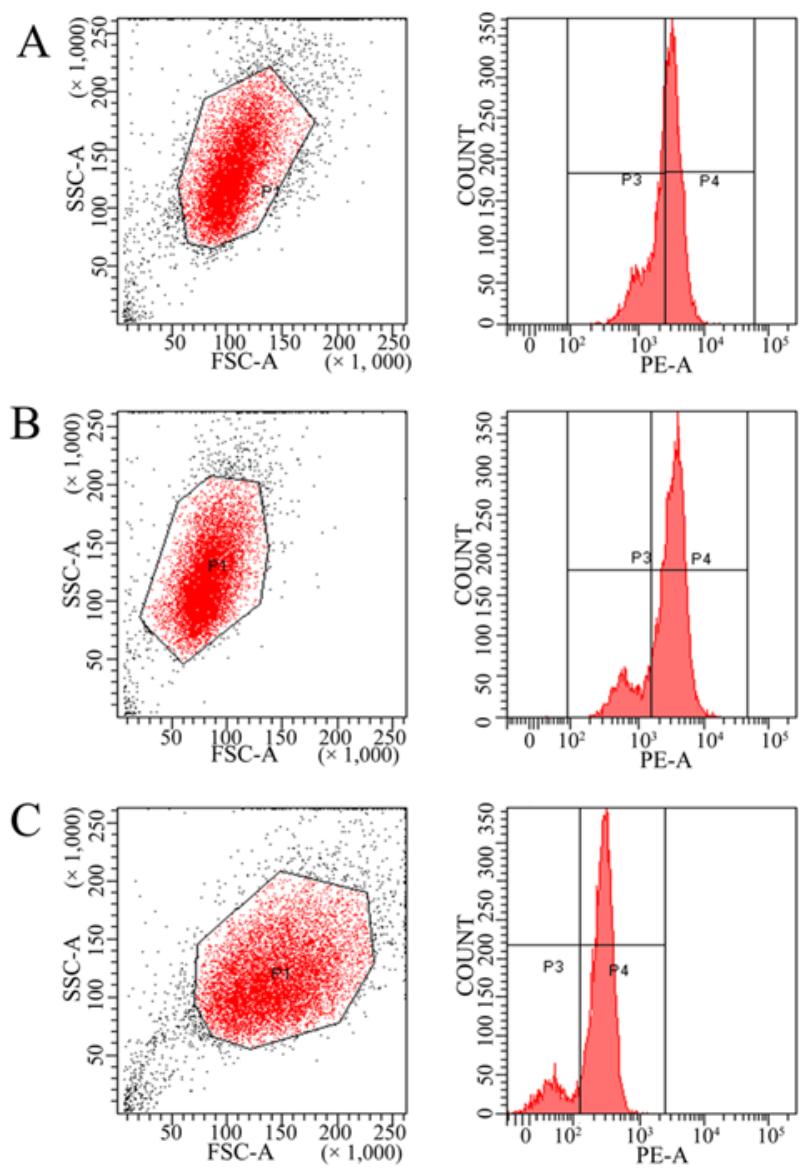

Figure 3. Transfer efficiency of Cy3-labeled miR-21 mimics into recipient cells. The transfer efficiency of Cy3-labeled miR-21 mimics into recipient cells was $60.3 \%$ (A), $82.6 \%$ (B), and $85.0 \%$ (C) after 3,6 and $24 \mathrm{~h}$ of culture, respectively, through flow cytometry. P1 represents the gating cells, $\mathrm{P} 3$ represent the cells without fluorescence, and P4 signifies the fluorescent cells.

Extracellular miR-21 can be transfected to recipient cells by EC9706 cell-derived exosomes. To determine whether miR-21 can be shuttled by donor EC9706 cell-derived exosomes, Cy3-labeled miR-21 mimics were transfected to donor EC9706 cells. In addition, culture medium from donor cells was added to recipient EC9706 cells. After the donor EC9706 cells were transfected for $48 \mathrm{~h}$, the miR-21 expression level in donor cells was increased with a 71.87-fold change compared with the negative control group; thus, the synthetic miR-21 has been transfected successfully. Flow cytometric analysis 

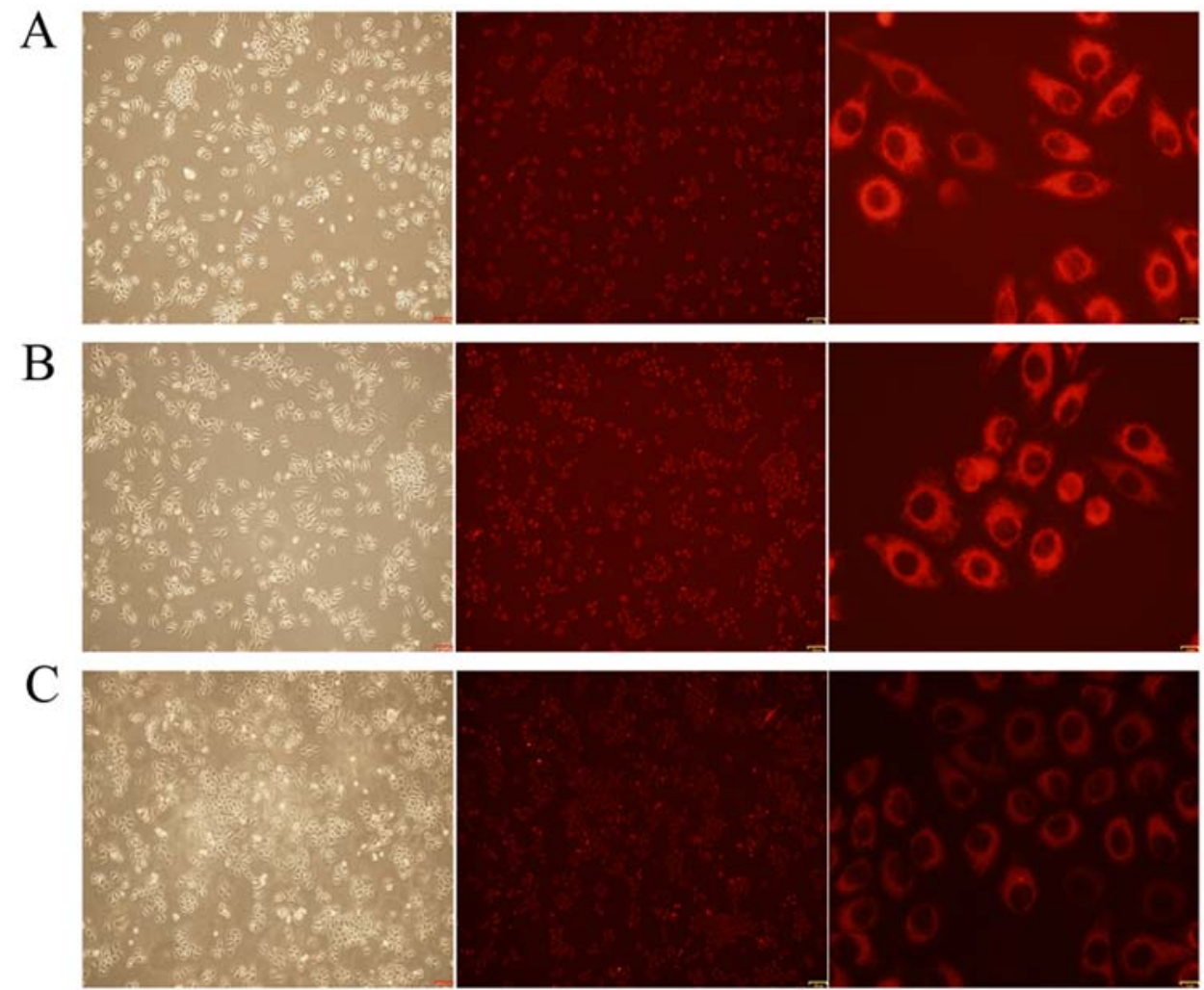

Figure 4. Images of Cy3-labeled miR-21 transferred to recipient EC9706 cells via donor EC9706 cell-derived exosomes. Images of Cy3-labeled miR-21 transferred to recipient EC9706 cells via donor EC9706 cell-derived exosomes were captured by fluorescent microscope in (A) $3 \mathrm{~h}$, (B) $6 \mathrm{~h}$ and (C) $24 \mathrm{~h}$ Fluorescence was not detected in recipient cells that were not cultured with the medium from donor cells or that were cultured with the donor EC9706 cells, which were transfected with unlabeled miR-21. The pictures on the left represent recipient EC9706 cells in bright light (x40 magnified). Pictures in the middle represent recipient EC9706 cells under fluorescence (x40 magnified). The pictures on the right represent a part of recipient EC9706 cells from the middle pictures under the fluorescence (x200 magnified).
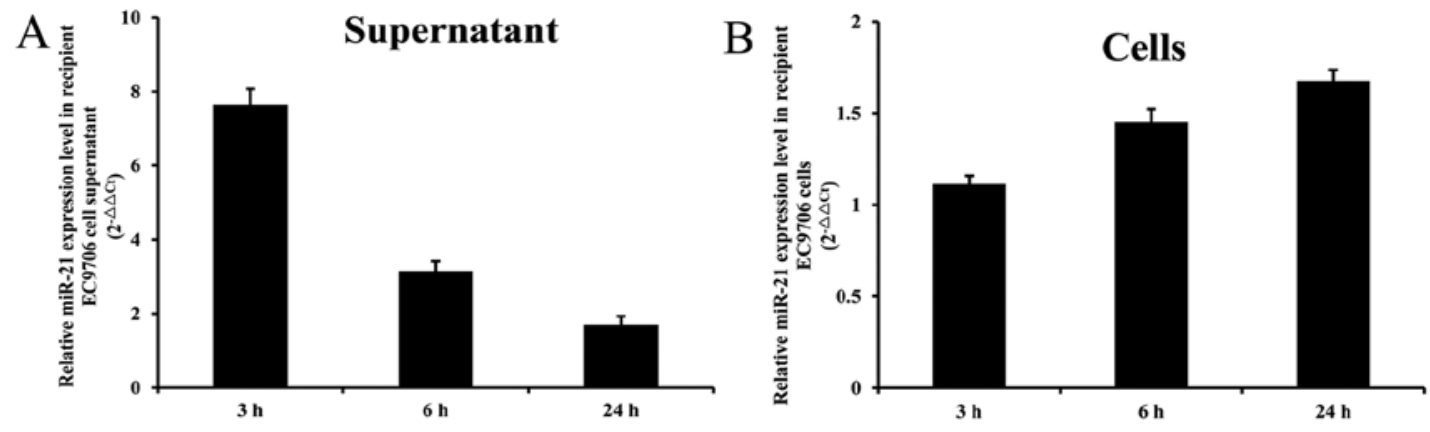

Figure 5. miR-21 expression levels in EC9706-culture medium and recipient EC9706 cells after culture medium from donor cells were added to recipient EC9706 cells. RT-qPCR analysis of miR-21 expression in EC9706-culture medium (A) and recipient EC9706 cells (B) after donor cells were transfected with miR-21 and miR-negative control mimics. RNU6 was used as internal control for cells to normalize the results. Data are presented as mean \pm SD.

showed that the transfer efficiency of Cy3-labeled miR-21 mimics into recipient cells was $60.3,82.6$ and $85.0 \%$ after 3 , 6 and $24 \mathrm{~h}$ of culture, respectively. Therefore, the Cy3-labeled miR-21 was transferred by the recipient cells (Fig. 3). Fig. 4 shows that recipient EC9706 cells treated with culture medium from donor EC9706 cells were fluorescently labeled under fluorescence microscope. RT-qPCR results showed that the expression level of miR-21 in miR-21 mimics-transfected group was higher than the negative control group, with an average fold change of 1.11, 1.45 and 1.67 in recipient cells (Fig. 5A) and the expression levels were 7.64, 3.15, 1.69 in culture supernatant (Fig. 5B) after 3, 6 and 24 h of culture, respectively. The results showed that miR-21 was suggested to be secreted from donor EC9706 cells and was delivered into recipient EC9706 cells via exosomes.

nSMase inhibits the release of EC9706 cell derive-exosomes. Recent reports show that miRNAs can be incorporated into exosomes and released via a ceramide-dependent pathway (25). Ceramide is a kind of fatty acid molecule whose biosynthesis is regulated by nSMase2, which is known to hydrolyze sphingomyelins to generate ceramides and trigger the budding of exosomes (26). In the present study, to evaluate whether the miR-21 secretion depends on exosome transfer, we treated 

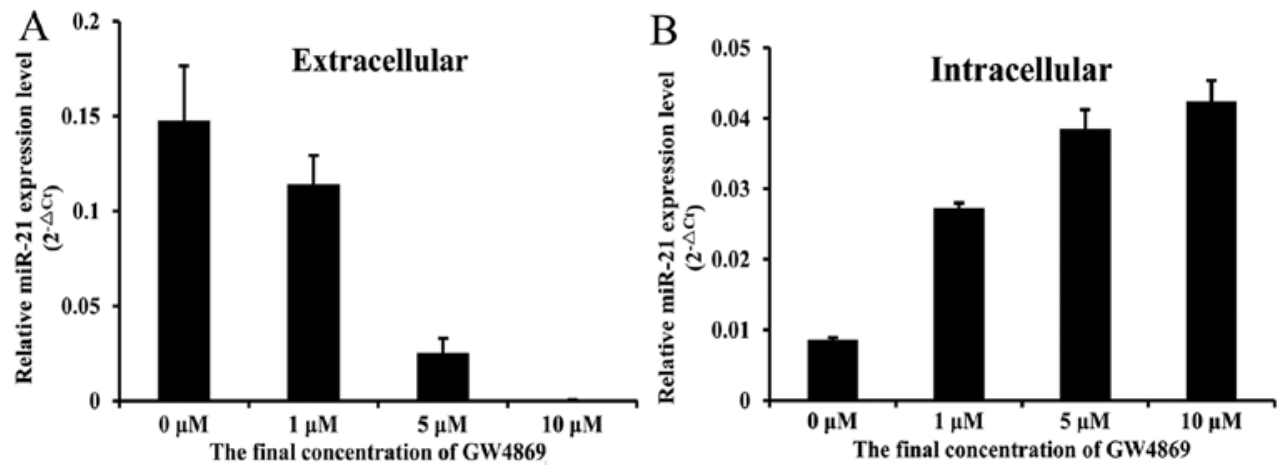

Figure 6. miR-21 secretion was suppressed by the GW4869 treatment. EC9706 cells were seeded and cultured in a 24 -well plate for $48 \mathrm{~h}$ in the indicated GW4869 concentrations. After the incubation, the cells and culture medium were subjected to RT-qPCR for miR-21. Results showed that the miR-21 expression in culture medium obtained from these cells was reduced (A), whereas the miR-21 cellular expression was increased after incubation with GW4869. These results were based on the comparison with the controls (B). RNU6 and cel-miR-39 were used as internal controls for cells and culture medium, respectively, to normalize the results. Data are presented as mean $\pm \mathrm{SD}$.

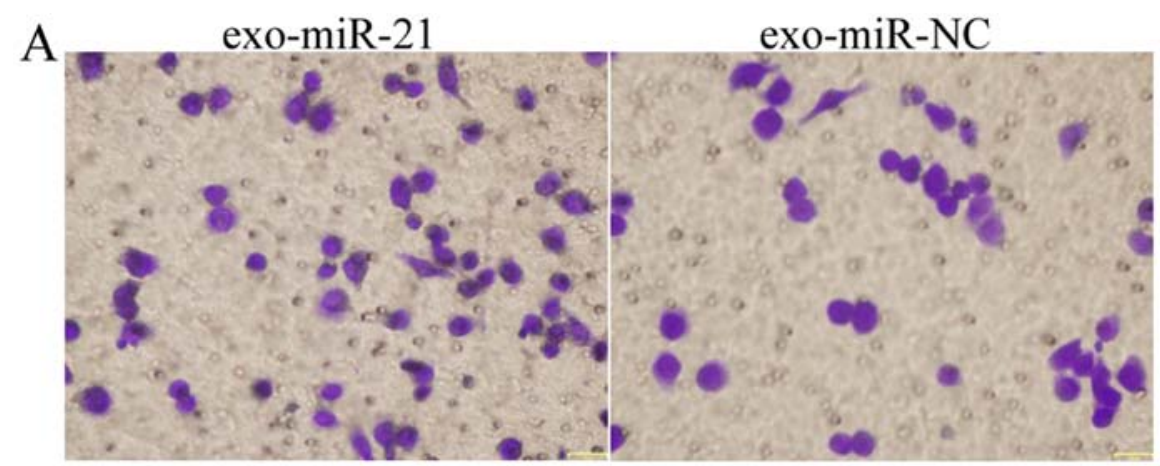

B

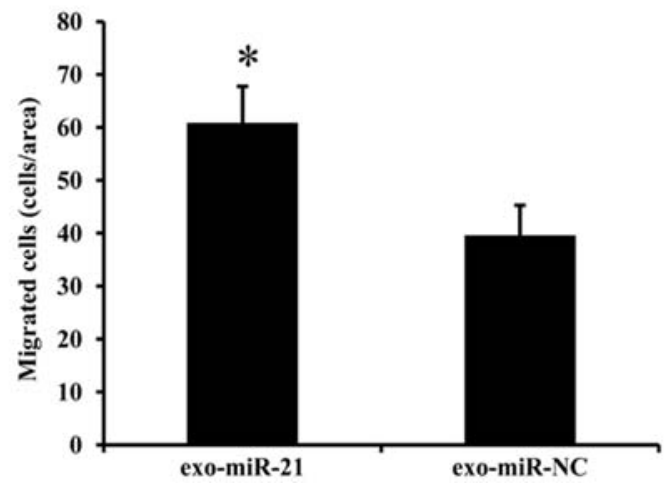

Figure 7. miR-21 effect on the migration of recipient EC9706 cells after co-cultivation. EC9706 cells were transfected with miR-21 mimics or control at a $30 \mathrm{nM}$ final concentration. (A) Representative photographs of migrated recipient EC9706 cells on the membrane at a x200 magnification. (B) Migration rate of recipient EC9706 cells that passed through the polycarbonate membrane. Exo-miR-21 is the group of recipient cells co-cultured with miR-21 mimicstransfected donor EC9706 cells. Exo-miR-NC is the group of recipient cells co-cultured with miR-negative control mimics-transfected donor EC9706 cells. Results are presented as mean $\pm \mathrm{SD} .{ }^{*} \mathrm{P}<0.05$ vs. exo-miR-NC group.

EC9706 cells with GW4869, which is an nSMase2 inhibitor, and examined the miR-21 expression level in donor cells and their culture medium. As a result of this treatment, the miR-21 expression levels in extracellular (Fig. 6A) and intracellular conditions (Fig. 6B) were dose-dependent at various GW4869 concentrations. The extracellular miR-21 expression in exosomes was reduced when the GW4869 concentration was increased, whereas the miR-21 cellular expression was increased after incubation with GW4869. These findings were based on the comparison with the controls. These data showed that the GW4869 treatment reduced the expression level of exosome-shuttling miR-21.
Exosome-shuttling miR-21 promotes recipient cell migration. Cell migration assay was detected using an $8 \mu \mathrm{M}$ pore transwell as described in Materials and methods. We tested the potential migration capacity of miR-21-transfected donor EC9706 cell-derived exosomes on the recipient cells through the co-cultivation model. Results showed that co-culture with miR-21-transfected donor EC9706 cells enhanced the migration of recipient cells relative to the miR-NC-transfected group with an average fold change of 1.54 (Fig. 7). These data suggest that exosomes, derived from donor EC9706 cells with enforced miR-21 expression, can be transferred to and affect the migration of recipient cells. 


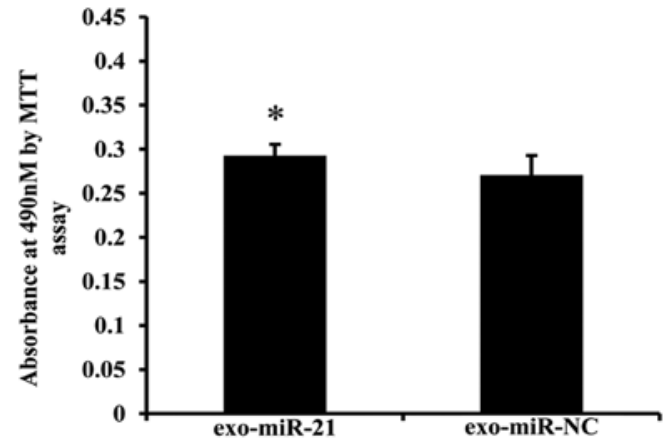

Figure 8. miR-21 effect on the invasiveness of recipient EC9706 cells after co-cultivation. Cell invasion assays of recipient EC9706 cells were performed using MTT method. Exo-miR-21 is the group of recipient cells cocultured with miR-21 mimic-transfected donor EC9706 cells. Exo-miR-NC is the group of recipient cells co-cultured with miR-negative control mimictransfected donor EC9706 cells. Results are presented as mean \pm SD. ${ }^{*} \mathrm{P}<0.05$ vs. exo-miR-NC group.

Exosome-shuttling miR-21 promotes recipient cell invasion. In the invasiveness assay, cell co-cultivation was performed using an $8 \mu \mathrm{M}$ pore Transwell with Matrigel-coated inserts as described in Materials and methods. We tested the potential biological function of miR-21-transfected donor EC9706 cellderived exosomes on the recipient cells through co-cultivation model. Results showed that co-culture with miR-21-transfected donor EC9706 cells enhanced the invasiveness of recipient cells compared with the miR-NC-transfected group with an average fold change of 1.08 (Fig. 8). Our results showed that EC9706-derived exosome-shuttling miR-21 can be transferred to and affect the invasive ability of recipient cells.

Exosome-shuttling miR-21 represses PDCD4 protein expression by binding to 3'-UTR. To determine whether donor cell-derived exosome-shuttling miRNA exerts regulatory action on its target gene in recipient cells, we examined the expression of PDCD4, which is a predicted target gene for miR-21 (27-29). As predicted by TargetScan, the 3'-UTR regions from PDCD4 contain the miR-21 binding site(s) with a seven-mer seed match (Fig. 9A). Luciferase reporter assay was used to identify whether PDCD4 is a direct target gene of miR-21. Results revealed that miR-21 overexpression in EC9706 cells significantly reduced luciferase activity of pmiR-Report-WT-PDCD4 plasmid with a $25.1 \%$ reduction. However, this process proceeded without changes in the luciferase activity of pmiR-Report-MUT-PDCD4. These results indicated that miR-21 directly binds the 3'-UTR of PDCD4 genes (Fig. 9B). We performed western blot analysis to detect the PDCD4 protein expression level in recipient EC9706 cells after a $24 \mathrm{~h}$ co-culture. Fig. $9 \mathrm{C}$ shows that exosomes from
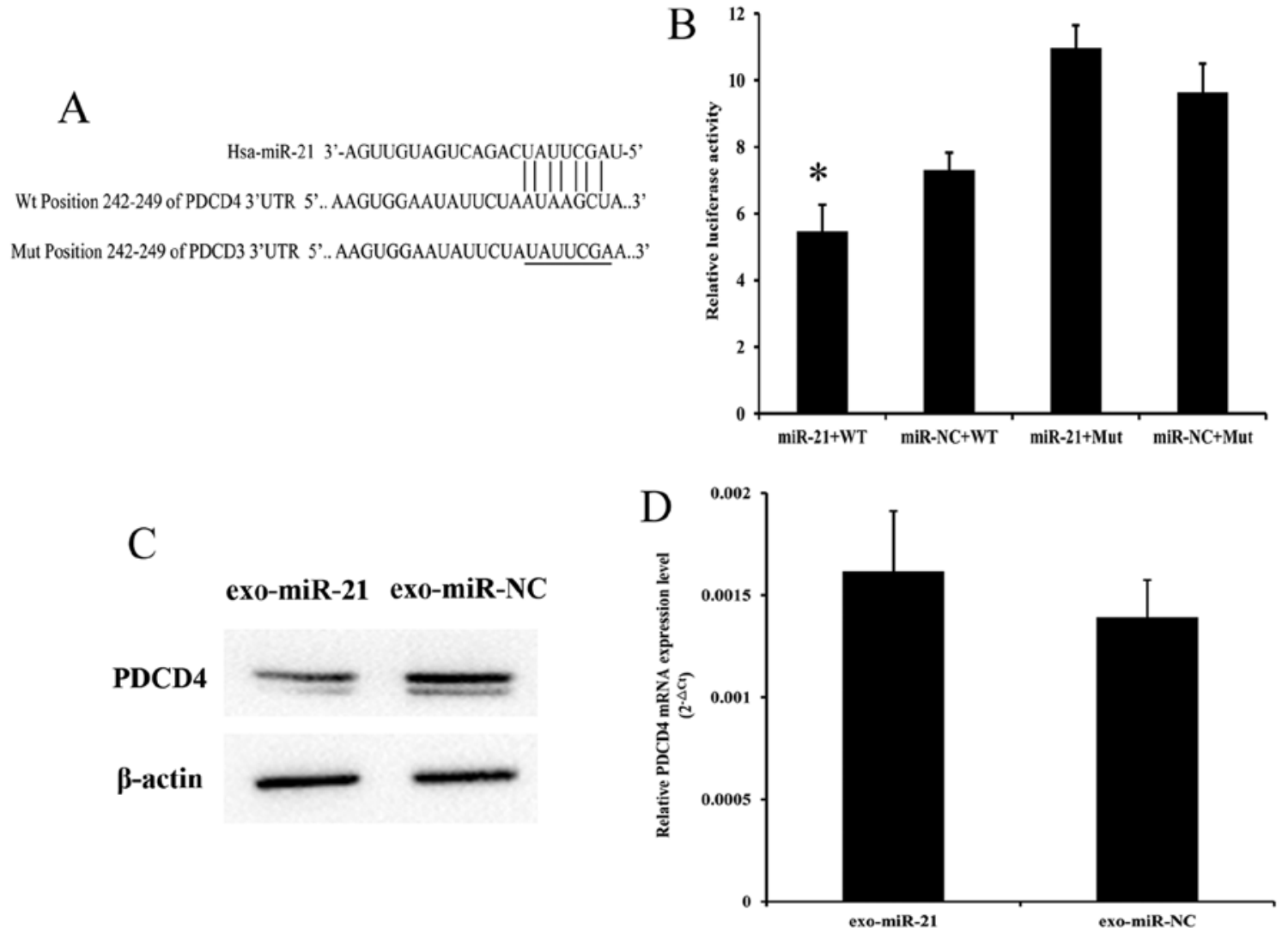

Figure 9. Exosome-shuttling miR-21 represses PDCD4 protein expression by binding to 3'-UTR. (A) Prediction result of TargetScan (http://www.targetscan. org/): PDCD4-3'-UTR contains reporter constructs of miR-21. (B) EC9706 cells were transfected with wild reporter plasmid or mutation reporter plasmid and miR-21 mimics. EC9706 luciferase activity was measured $48 \mathrm{~h}$ after transfection by Luciferase Assay System. WT is the plasmid construct that contains PDCD4 3'-UTR wild-type. Mut is the plasmid construct that contains PDCD4 3'-UTR mutant type. * $\mathrm{P}<0.05$ vs. miR-NC+WT. (C) Western blot gel for PDCD4 protein level in recipient cells after $24 \mathrm{~h}$ co-cultivation. (D) PDCD4 mRNA levels in recipient cells detected by qRT-PCR at $24 \mathrm{~h}$ after co-cultivation. Exo-miR-21 is the group of recipient cells co-cultured with miR-21 mimics-transfected donor EC9706 cells. Exo-miR-NC is the group of recipient cells cocultured with miR-negative control mimic-transfected donor EC9706 cells. Results are presented as mean \pm SD. ${ }^{*} \mathrm{P}<0.05$ vs. exo-miR-NC group. 


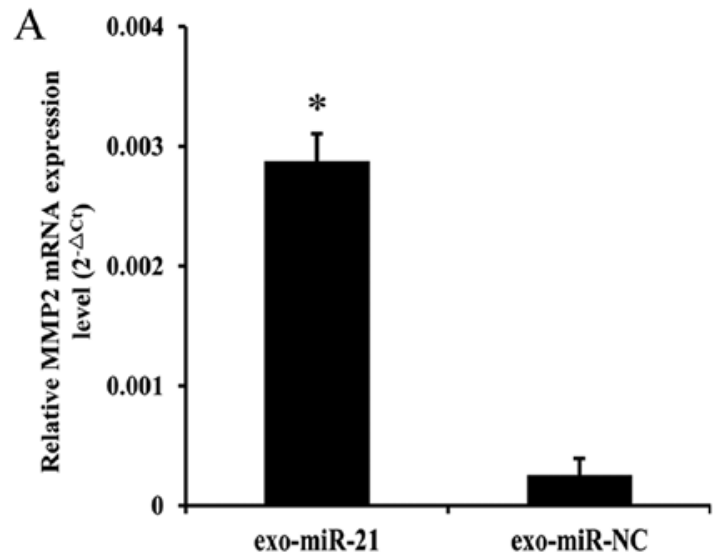

$\mathrm{C}$

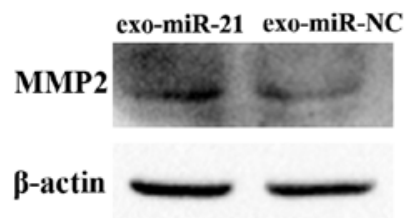

$\mathrm{B}$

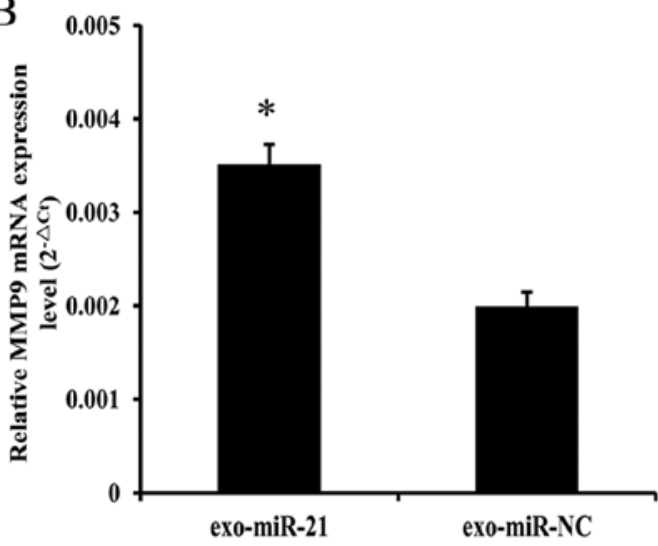

$\mathrm{D}$

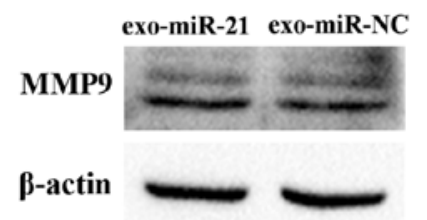

Figure 10. The expression levels of MMP-2 and MMP-9 mRNA and protein in recipient EC9706 cells after co-cultivation. miR-21 overexpression in donor EC9706 cells increased MMP-2 and MMP-9 mRNA (A and B) and protein (C and D) expression level of recipient cells. Exo-miR-21 is the group of recipient cells co-cultured with miR-21 mimic-transfected donor EC9706 cells. Exo-miR-NC is the group of recipient cells co-cultured with miR-negative control mimic-transfected donor EC9706 cells. Results are presented as mean \pm SD. ${ }^{*} \mathrm{P}<0.05$ vs. exo-miR-NC group.

Table II. Characteristics of ESCC patients and healthy controls.

\begin{tabular}{lcc}
\hline Variables & $\begin{array}{c}\text { No. of ESCC } \\
\text { patients (n=67) }\end{array}$ & $\begin{array}{c}\text { No. of healthy } \\
\text { controls (n=67) }\end{array}$ \\
\hline $\begin{array}{l}\text { Age (years) } \\
\text { Smoking index }\end{array}$ & $61.82 \pm 8.14$ & $63.03 \pm 9.66$ \\
$\quad$ Never & $32^{\mathrm{a}}$ & 48 \\
Ever $^{\mathrm{c}}$ & & \\
$\quad<400$ & 8 & 5 \\
$\geq 400$ & 27 & 14 \\
Alcohol consumption & & \\
Never & $33^{\mathrm{a}}$ & 48 \\
Ever & & \\
Family history & 34 & 19 \\
No & & 67 \\
Yes & $58^{\mathrm{a}}$ & 0 \\
\hline
\end{tabular}

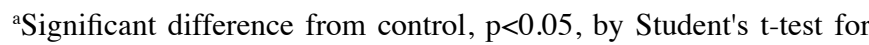
age, $\chi^{2}$ test for smoking, alcohol use, and family history. ${ }^{\mathrm{b}}$ Smoking index $=$ cigarettes/day $\mathrm{x}$ smoking years. ${ }^{\mathrm{c}}$ Smoked $>100$ cigarettes in lifetime. ${ }^{\mathrm{d}}$ Drank at least once a month.

miR-21-transfected EC9706 cells significantly downregulated PDCD4 protein expression with a $22.27 \%$ reduction in recipient cells under the co-cultivation model. RT-qPCR was performed to detect the RNA levels of PDCD4. Results showed that no statistically significant change in PDCD4 mRNA expression existed between the miR-21 mimics and the negative control group ( $\mathrm{P}>0.05$; Fig. 9D). These results suggest that miR-21 secreted by donor EC9706 cells can be effectively uptaken by recipient EC9706 cells and regulate PDCD4 expression at a post-transcriptional level in the recipient cells.

miR-21 overexpression increases MMP-2 and MMP-9 expression. Expression of MMP-2 and MMP-9 involved in metastasis was tested to investigate whether exosomeshuttling miR-21 regulates esophageal cancer cell migration and invasion. RT-qPCR was used to determine the MMP-2 mRNA and MMP-9 mRNA expression levels in recipient cells after co-cultivation. Compared with the miR-negative control group, the MMP-2 mRNA and MMP-9 mRNA expression levels showed an 11.24- and 1.76-fold increase, respectively, in miR-21 mimics group (Fig. 10A and B). Western blot analysis was used to determine the expression levels of MMP-2 and MMP-9 proteins in recipient cells after co-cultivation. Compared with the miR-negative control group, the expression levels of MMP-2 and MMP-9 proteins showed a 13.84- and 5.83 -fold increase, respectively, in miR-21 mimics group (Fig. 10C and D). These data suggest that exosome-shuttling miR-21 inhibits target PDCD4 expression at translational level and plays an important role in the JNK downstream signaling pathway involved in tumor migration and invasion.

Case-control study on the association between exosome-shuttling miR-21 and esophageal cancer incidence. The smoking status, alcohol use and family history of ESCC patients and healthy controls are shown in Table II. The average ages of cancer patients and controls were not significantly different. The difference was statistically significant in the distribution of smoking, alcohol use, and cancer family history between 
Table III. Relative expression of miR-21 in plasma from ESCC patients and healthy controls.

\begin{tabular}{lccccccc}
\hline Group & miRNA & Mean $\pm \mathrm{SD}$ of $\Delta \mathrm{Ct}^{\mathrm{a}}$ & $\Delta \Delta \mathrm{Ct}^{\mathrm{a}}$ & $2^{-\Delta \Delta \mathrm{Ct}}$ & OR & $95 \% \mathrm{CI}$ & P-value \\
\hline Case $\mathrm{b}^{\mathrm{c} c \mathrm{c}}$ & $\mathrm{miR}-21$ & $-2.39 \pm 4.03$ & -1.56 & 2.95 & 1.107 & $1.012-1.21$ & 0.026 \\
Control & miR-21 & $-0.83 \pm 3.86$ & & & & & \\
\hline
\end{tabular}

${ }^{\mathrm{a}} \Delta \mathrm{Ct}=\mathrm{Ct}_{\mathrm{miR}-21}-\mathrm{Ct}_{\mathrm{U} 6}, \Delta \Delta \mathrm{Ct}=\Delta \mathrm{Ct}_{\text {case }}-\Delta \mathrm{Ct}_{\text {control }}$. ${ }^{\mathrm{b}}$ Significant difference from control, $\mathrm{P}<0.05$. ${ }^{\mathrm{c}}$ With paired $\mathrm{t}$-test performed to determine the significant difference.

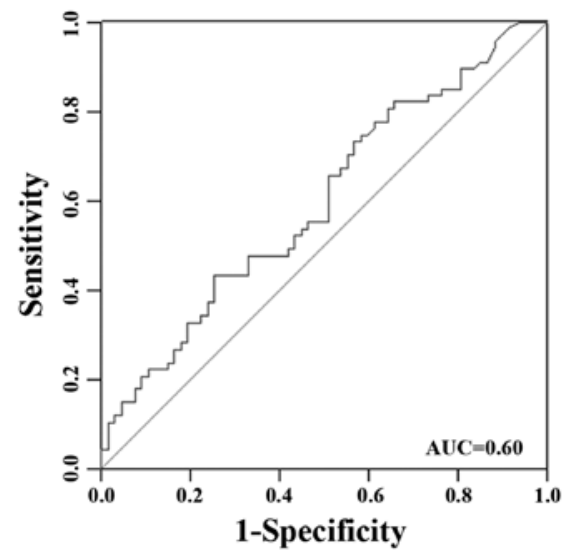

Figure 11. Receiver operating characteristic (ROC) plot of circulating miR-21. Data were used to draw the ROC plot. The curve for miR-21 (upper line) was used to discriminate plasma from esophageal cancer patients and healthy controls and the area under the curve (AUC) was used to evaluate the level of discrimination. Diagonal reference line (lower line) is the random guess line with no discrimination.

patients and healthy controls. Paired t-test was used to assess the differences between the plasma recruited from esophageal cancer patients and healthy controls. Table III shows that the relative expression of miR-21 was upregulated, with a fold change of 2.95 , in the patients' plasma when compared with plasma from healthy controls. Furthermore, conditional logistic regression analysis showed that a significantly increased risk for esophageal cancer was associated with increased miR-21 expression (OR, 1.107; 95\% CI, 1.012-1.21; P=0.026). Receiver operating characteristic (ROC) curve was generated to see the power of exosome-shuttling miR-21 to distinguish ESCC patients from healthy controls. The area under the curve was used as a measurement for level of discrimination. As shown in Fig. 11, circulating miR-21 discrimination of esophageal cancer from healthy person was noted by an area-under-thecurve (AUC) value of 0.60 .

\section{Discussion}

Emerging evidence suggests that tumor microenvironment plays an important role in tumor occurrence and development (30). Cell-cell communication is an indispensably dynamic mechanism, which results in normal cellular activities and tissue homeostasis maintenance (31). The mechanisms of cell-cell communication were as follows: i) integral membrane protein-mediated direct cell-cell contact; ii) indirect contact via the extracellular matrix; and iii) circulating miRNA via exosomes or extracellular miRNA such as the Ago2-binding
miRNA in the extracellular microenvironment (19). Recently, the roles of tumor cell-derived exosomes in cell-cell communication of tumor microenvironment are gradually revealed. Research has shown that exosomes could be internalized into the cells through endocytosis but not incorporated into the plasma membrane (24). We applied a cell culture chamber of the 3D live-cell imaging system to observe the exosome transfer process. Our results showed that DiI-labeled exosomes could be taken up from the extracellular environment to the cytoplasm by EC9706 cells. Studies have indicated that microvesicles released from the endosomal component or fused with the plasma membrane can directly affect target cells by receptormediated interaction or by transferring biological information molecules, such as miRNAs (32). Studies have proposed that the transfer of exosome-derived unique miRNA to recipient cells is an alternative mechanism that involves direct cell-cell contact or chemical receptor-mediated events, which allow gene-based communication between cells (16). miRNAs found in the macrophage-derived microvesicles were shuttled not only to monocytic cells but also to other cell lineages. Thus, macrophage-derived microvesicles could communicate with various cell types, which include allogeneic cells or cell types that are different from the donor cell; this finding signifies a widespread impact (33). Shimbo et al (34) found that synthetic miR-143 transfected into bone-marrow-derived mesenchymal stem cells (MSCs) was enveloped in exosomes. MSC-derived exosome-formed miR-143 could be transferred to osteosarcoma cells and could affect osteosarcoma cell migration. A study on breast cancer showed that miR-223, which was within the exosomes released by macrophages, could promote breast cancer cell invasion via the Mefc- $\beta$-catenin pathway under a co-culture system (23). As a result, miRNA may be secreted and delivered into recipient cells via exosomes after donor cell transfection. These secreted miRNAs may alter the cellular functions of the recipient cells by modulating the expression of their target genes. This process may play an important role in mediating tumor microenvironment.

miR-21, which is considered an oncomiR, is demonstrated to be overexpressed in numerous tumor tissues, cells, or body fluids from tumor patients (35-37). Many studies have been conducted on the function of miR-21 in tumor occurrence and development. These studies showed that miR-21 could promote cell growth, proliferation, invasion and metastasis of various tumor cells by targeting PTEN, PDCD4, RECK, FASL and TIMP3 (38-40). Hiyoshi et al (41) found that the inhibition of microRNA-21 could lead to a reduction of the proliferation and invasion in esophageal squamous cell carcinoma cell lines by increasing PDCD4 protein expression 
without changing the PDCD4 mRNA level by binding to the PDCD4-3' untranslated region. This finding suggests that microRNA-21 targets PDCD4 at the post-transcriptional level and regulates cell proliferation and invasion in esophageal squamous cell carcinoma. In the present study, we transfected donor EC9706 cells with Cy3-labeled miR-21 and showed the effective transfer of miR-21 from donor cells to recipient cells by flow cytometry and RT-qPCR. nSMase 2 was shown to hydrolyze sphingomyelins to generate ceramides and trigger exosome budding $(23,42)$. In a study on nSMase 2 and tumorderived exosomes, it was found that the expression level of nSMase 2 was higher in cancer cells than in non-cancer cells, and the secretion level of exosomes was correlated with the expression level of nSMase2 (43). In the present study, we used GW4869, which is an nSMase2 inhibitor, to confirm that miR-21 secretion is an exosome-dependent process. Results showed that with the inhibition of exosome secretion, the miR-21 expression level in culture supernatant gradually decreased. The abovementioned finding demonstrates that miR-21 could be shuttled between cells via exosomes, which provides the possibility for the function research of miR-21 in tumor cell-cell communication.

Subsequently, we constructed a Transwell co-culture system to imitate the tumor microenvironment and demonstrated that exosome-shuttling miR-21 promoted the migration and invasion of recipient EC9706 cells through Transwell insert assay. PDCD4, a tumor suppressor gene, was demonstrated to have low expression in various tumor tissues and cells $(44,45)$. PDCD4, which was predicted to be a miR-21 target gene by TargetScan, has been reported to be a key regulator of tumor proliferation, apoptosis, adhesion, migration, invasion and metastasis $(28-30,40,46)$. Tumor invasion is a multistep process in which cell motility is coupled with proteolysis and involves interaction of cells with extracellular matrix (ECM). MMP-2 and MMP-9 are released as latent enzymes, which are capable of degradation of ECM involved in the invasion process. Studies showed that these enzymes were involved in cell migration through the removal of adhesion sites, cleavage of cell-cell or cell-matrix receptors, and release of chemoattractants from $\operatorname{ECM}(47,48)$. The invasiveness of U87MG glioblastoma cells was inhibited after the cells were treated with miR-21 inhibitor, which was mediated by an increase in PDCD4 expression and reduction of MMP-2 protein expression (49). Zhu et al (50) revealed that inhibition of miR-21 expression repressed cell migration and invasion through the miR-21-PDCD4-AP-1 feedback loop, which is involved in several key downstream signaling pathway molecules, such as phosphorylated c-Jun, MMP-2 and MMP-9. Another research on hepatocellular carcinoma found that PDCD4 overexpression suppressed JNK activity; moreover, JNK inhibition resulted in the suppression of the phosphorylated eIF4E, which may influence the invasion via regulation of MMP expression $(51,52)$. In the present study, we demonstrated that exosome-shuttling miR-21 from donor cells downregulated PDCD4 and increased the downstream signal levels of MMP-2 and MMP-9 in recipient cells. Our results suggested that the modulation of PDCD4 expression and downstream signaling regulation by exosome-mediated signal transfer may provide a novel mechanism of tumor progression.
Several studies have found that exosomal miRNAs could be secreted into the plasma and may be potential biomarkers in the diagnosis of different cancer types. A study on exosomal miRNAs from ovarian cancer showed that the levels of eight microRNAs, such as miR-21, miR-141 and miR-200a, were similar between cellular and exosomal miRNAs, with the correlation coefficients distributed from 0.71 to 0.90 . Thus, tumor exosomal miRNAs could be used as surrogate diagnostic markers for biopsy profiling (15). Another study on serum exosomes from esophageal cancer showed that miR-21 was not detected in the serum that remained after exosomes were extracted; this result suggested that exosomes from tumor cells are a major source of serum circulating miR-21 in esophageal cancer patients (43). Ogata-Kawata et al (53) found that the amount of seven serum exosomal miRNAs (i.e., let-7a, miR-1229, miR-1246, miR-150, miR-21, miR-223 and miR-23a) from the serum of TNM stage I colorectal cancer patients were significantly higher than in healthy controls; this finding suggested that serum exosomal miRNAs may serve as significant biomarkers for the early detection of primary colorectal cancer (53). One study of pancreatic adenocarcinoma (PC) found that serum exosomal miR-17-5p and miR-21 were significantly elevated in the advanced stage and metastatic PC patients; moreover, the diagnostic sensitivity and specificity were 72.7 and $92.6 \%$ for miR-17-5p and 95.5 and $81.5 \%$ for miR-21, respectively (54). In the present study, microarray analysis of plasma from esophageal cancer patients and healthy controls identified 20 miRNAs that could distinguish the plasma from ESCC patients and healthy controls. Among these miRNAs, miR-25-3p, miR-93-5p, miR-21-5p and miR-1290 were upregulated in cancer tissues and plasma/serum of various cancer patients and were confirmed to be oncogenes. miR-16-5p, miR-130a-3p, miR-15a-5p, miR-144-3p, miR-19b-3p, miR-107 and let-7i-5p may be tumor promotors or suppressors in different tumors with their dysregulated expression level. Few studies have focused on miR-5196-5p, miR-1914-3p, miR-3911, let-7d-3p, miR-1238-3p, miR-6069, miR-191-3p, miR-4665-3p and miR-937-5p. The results of the present study indicated that miR-21 is upregulated significantly in the plasma of esophageal cancer patients. In addition, a significant association was identified between miR-21 and esophageal cancer risk. These findings suggest that increased exosome-shuttling miR-21 in plasma might be a candidate biomarker for esophageal cancer diagnosis and high-risk population screening.

In summary, we have recognized the uptake process of exosomes by esophageal cancer cells and found that Cy3-labeled miR-21 mimics could be transferred between esophageal cancer cells by exosomes. Furthermore, our results revealed that miR-21 mimics could affect migration and invasion of recipient cells partly via modulation of its target gene PDCD4 and its downstream-signaling molecules, MMP-2 and MMP-9 by using the cell co-culture system. As a novel mechanism of cell-cell communication, the transfer of exosome-shuttling miR-21 is in addition to the classical mechanism and the effective delivery of exosome-shuttling miR-21 in tumor microenvironment may affect the status of esophageal cancer cells consequently to promote the recurrence and distant metastasis of esophageal cancer, which 
suggests that exosome-shuttling miR-21 could be a potential biomarker in esophageal cancer diagnosis.

\section{Acknowledgements}

The present study was supported by the National Natural Science Foundation of China (nos. 81172747, 81573108 and 81573191), the Natural Science Foundation of Jiangsu Province, China (no. BK2010407) and the New Century Excellent Talents in University from Ministry of Education, China (NCET-13-0124).

\section{References}

1. Ferlay J, Shin HR, Bray F, Forman D, Mathers C and Parkin DM: Estimates of worldwide burden of cancer in 2008: GLOBOCAN 2008. Int J Cancer 127: 2893-2917, 2010.

2. Wang KK and Sampliner RE; Practice Parameters Committee of the American College of Gastroenterology: Updated guidelines 2008 for the diagnosis, surveillance and therapy of Barrett's esophagus. Am J Gastroenterol 103: 788-797, 2008.

3. Kosaka N, Iguchi $\mathrm{H}$ and Ochiya T: Circulating microRNA in body fluid: A new potential biomarker for cancer diagnosis and prognosis. Cancer Sci 101: 2087-2092, 2010.

4. Cazzoli R, Buttitta F, Di Nicola M, Malatesta S, Marchetti A, Rom WN and Pass HI: microRNAs derived from circulating exosomes as noninvasive biomarkers for screening and diagnosing lung cancer. J Thorac Oncol 8: 1156-1162, 2013.

5. Manterola L, Guruceaga E, Gállego Pérez-Larraya J, GonzálezHuarriz M, Jauregui P, Tejada S, Diez-Valle R, Segura V, Samprón N, Barrena C, et al: A small noncoding RNA signature found in exosomes of GBM patient serum as a diagnostic tool. Neuro Oncol 16: 520-527, 2014.

6. Liu R, Liao J, Yang M, Shi Y, Peng Y, Wang Y, Pan E, Guo W, $\mathrm{Pu} \mathrm{Y}$ and Yin L: Circulating miR-155 expression in plasma: A potential biomarker for early diagnosis of esophageal cancer in humans. J Toxicol Environ Health A 75: 1154-1162, 2012.

7. Ali S, Almhanna K, Chen W, Philip PA and Sarkar FH: Differentially expressed miRNAs in the plasma may provide a molecular signature for aggressive pancreatic cancer. Am J Transl Res 3: 28-47, 2010.

8. Wang HY, Yan LX, Shao Q, Fu S, Zhang ZC, Ye W, Zeng YX and Shao JY: Profiling plasma microRNA in nasopharyngeal carcinoma with deep sequencing. Clin Chem 60: 773-782, 2014.

9. Cheng L, Sharples RA, Scicluna BJ and Hill AF: Exosomes provide a protective and enriched source of miRNA for biomarker profiling compared to intracellular and cell-free blood. J Extracell Vesicles 3: 3, 2014.

10. Ge Q, Zhou Y, Lu J, Bai Y, Xie X and Lu Z: miRNA in plasma exosome is stable under different storage conditions. Molecules 19: $1568-1575,2014$

11. Salido-Guadarrama I, Romero-Cordoba S, Peralta-Zaragoza O, Hidalgo-Miranda A and Rodríguez-Dorantes M: MicroRNAs transported by exosomes in body fluids as mediators of intercellular communication in cancer. Onco Targets Ther 7: $1327-1338,2014$

12. Ramachandran S and Palanisamy V: Horizontal transfer of RNAs: Exosomes as mediators of intercellular communication. Wiley Interdiscip Rev RNA 3: 286-293, 2012.

13. Kosaka N, Yoshioka Y, Hagiwara K, Tominaga N, Katsuda T and Ochiya T: Trash or treasure: Extracellular microRNAs and cellto-cell communication. Front Genet 4: 173, 2013

14. Rabinowits G, Gerçel-Taylor C, Day JM, Taylor DD and Kloecker GH: Exosomal microRNA: A diagnostic marker for lung cancer. Clin Lung Cancer 10: 42-46, 2009.

15. Taylor DD and Gercel-Taylor C: MicroRNA signatures of tumorderived exosomes as diagnostic biomarkers of ovarian cancer. Gynecol Oncol 110: 13-21, 2008.

16. Tadokoro H, Umezu T, Ohyashiki K, Hirano T and Ohyashiki JH: Exosomes derived from hypoxic leukemia cells enhance tube formation in endothelial cells. J Biol Chem 288: 34343-34351, 2013.

17. Nouraee N, Van Roosbroeck K, Vasei M, Semnani S, Samaei NM, Naghshvar F, Omidi AA, Calin GA and Mowla SJ: Expression, tissue distribution and function of miR-21 in esophageal squamous cell carcinoma. PLoS One 8: e73009, 2013.
18. Singh R, Pochampally R, Watabe K, Lu Z and Mo YY: Exosomemediated transfer of miR-10b promotes cell invasion in breast cancer. Mol Cancer 13: 256, 2014.

19. Umezu T, Ohyashiki K, Kuroda M and Ohyashiki JH: Leukemia cell to endothelial cell communication via exosomal miRNAs. Oncogene 32: 2747-2755, 2013.

20. Liao J, Liu R, Yin L and Pu Y: Expression profiling of exosomal miRNAs derived from human esophageal cancer cells by Solexa high-throughput sequencing. Int J Mol Sci 15: 15530-15551, 2014.

21. Han Y, Wei F, Xu X, Cai Y, Chen B, Wang J, Xia S, Hu H, Huang X, Han Y, et al: Establishment and comparative genomic hybridization analysis of human esophageal carcinomas cell line EC9706. Zhonghua Yi Xue Yi Chuan Xue Za Zhi 19: 455-457, 2002 (In Chinese).

22. Ji H, Erfani N, Tauro BJ, Kapp EA, Zhu HJ, Moritz RL, Lim JW and Simpson RJ: Difference gel electrophoresis analysis of Ras-transformed fibroblast cell-derived exosomes. Electrophoresis 29: 2660-2671, 2008.

23. Yang M, Chen J, Su F, Yu B, Su F, Lin L, Liu Y, Huang JD and Song E: Microvesicles secreted by macrophages shuttle invasionpotentiating microRNAs into breast cancer cells. Mol Cancer 10: 117,2011

24. Tian T, Wang Y, Wang H, Zhu Z and Xiao Z: Visualizing of the cellular uptake and intracellular trafficking of exosomes by live-cell microscopy. J Cell Biochem 111: 488-496, 2010.

25. Kosaka N, Iguchi H, Yoshioka Y, Takeshita F, Matsuki Y and Ochiya T: Secretory mechanisms and intercellular transfer of microRNAs in living cells. J Biol Chem 285: 17442-17452, 2010.

26. Kosaka N, Iguchi H, Yoshioka Y, Hagiwara K, Takeshita F and Ochiya T: Competitive interactions of cancer cells and normal cells via secretory microRNAs. J Biol Chem 287: 1397-1405, 2012.

27. Allgayer $\mathrm{H}: \mathrm{Pdcd} 4$, a colon cancer prognostic that is regulated by a microRNA. Crit Rev Oncol Hematol 73: 185-191, 2010.

28. Li L, Zhou L, Li Y, Lin S and Tomuleasa C: MicroRNA-21 stimulates gastric cancer growth and invasion by inhibiting the tumor suppressor effects of programmed cell death protein 4 and phosphatase and tensin homolog. J BUON 19: 228-236, 2014.

29. Liu T, Liu Q, Zheng S, Gao X, Lu M, Yang C, Dai F, Sheyhidin I and Lu X: MicroRNA-21 promotes cell growth and migration by targeting programmed cell death 4 gene in Kazakh's esophageal squamous cell carcinoma. Dis Markers 2014: 232837, 2014.

30. Kahlert $\mathrm{C}$ and Kalluri R: Exosomes in tumor microenvironment influence cancer progression and metastasis. J Mol Med Berl 91: 431-437, 2013.

31. Lee JK, Park SR, Jung BK, Jeon YK, Lee YS, Kim MK, Kim YG, Jang JY and Kim CW: Exosomes derived from mesenchymal stem cells suppress angiogenesis by down-regulating VEGF expression in breast cancer cells. PLoS One 8: e84256, 2013.

32. Tetta C, Ghigo E, Silengo L, Deregibus MC and Camussi G: Extracellular vesicles as an emerging mechanism of cell-to-cell communication. Endocrine 44: 11-19, 2013.

33. Ismail N, Wang Y, Dakhlallah D, Moldovan L, Agarwal K, Batte K, Shah P, Wisler J, Eubank TD, Tridandapani S, et al: Macrophage microvesicles induce macrophage differentiation and miR-223 transfer. Blood 121: 984-995, 2013.

34. Shimbo K, Miyaki S, Ishitobi H, Kato Y, Kubo T, Shimose $S$ and Ochi M: Exosome-formed synthetic microRNA-143 is transferred to osteosarcoma cells and inhibits their migration. Biochem Biophys Res Commun 445: 381-387, 2014.

35. Gao J, Zhang Q, Xu J, Guo L and Li X: Clinical significance of serum miR-21 in breast cancer compared with CA153 and CEA. Chin J Cancer Res 25: 743-748, 2013.

36. Gao W, Xu J, Liu L, Shen H, Zeng H and Shu Y: A systematicanalysis of predicted miR-21 targets identifies a signature for lung cancer. Biomed Pharmacother 66: 21-28, 2012.

37. Selcuklu SD, Donoghue MTA and Spillane C: miR-21 as a key regulator of oncogenic processes. Biochem Soc Trans 37: 918-925, 2009.

38. Wang N, Zhang CQ, He JH, Duan XF, Wang YY, Ji X, Zang WQ, Li M, Ma YY, Wang T, et al: MiR-21 down-regulation suppresses cell growth, invasion and induces cell apoptosis by targeting FASL, TIMP3, and RECK genes in esophageal carcinoma. Dig Dis Sci 58: 1863-1870, 2013.

39. Lou Y, Cui Z, Wang F, Yang X and Qian J: miR-21 down-regulation promotes apoptosis and inhibits invasion and migration abilities of OVCAR3 cells. Clin Invest Med 34: E281, 2011. 
40. Xu LF, Wu ZP, Chen Y, Zhu QS, Hamidi S and Navab R MicroRNA-21 (miR-21) regulates cellular proliferation, invasion, migration, and apoptosis by targeting PTEN, RECK and Bcl-2 in lung squamous carcinoma, Gejiu City, China. PLoS One 9: e103698, 2014.

41. Hiyoshi Y, Kamohara H, Karashima R, Sato N, Imamura Y, Nagai Y, Yoshida N, Toyama E, Hayashi N, Watanabe M, et al: MicroRNA-21 regulates the proliferation and invasion in esophageal squamous cell carcinoma. Clin Cancer Res 15: 1915-1922, 2009.

42. Tanaka Y, Kamohara H, Kinoshita K, Kurashige J, Ishimoto T, Iwatsuki M, Watanabe $M$ and Baba H: Clinical impact of serum exosomal microRNA-21 as a clinical biomarker in human esophageal squamous cell carcinoma. Cancer 119: 1159-1167, 2013.

43. Kosaka N, Iguchi H, Hagiwara K, Yoshioka Y, Takeshita F and Ochiya T: Neutral sphingomyelinase 2 (nSMase2)-dependent exosomal transfer of angiogenic microRNAs regulate cancer cell metastasis. J Biol Chem 288: 10849-10859, 2013.

44. Ma G, Zhang H, Dong M, Zheng X, Ozaki I, Matsuhashi S and Guo K: Downregulation of programmed cell death 4 (PDCD4) in tumorigenesis and progression of human digestive tract cancers. Tumour Biol 34: 3879-3885, 2013.

45. Wang D, Guo S, Han SY, Xu N, Guo JY and Sun Q: Distinct roles of different fragments of PDCD4 in regulating the metastatic behavior of B16 melanoma cells. Int J Oncol 42: 1725-1733, 2013.

46. Lankat-Buttgereit B and Göke R: The tumour suppressor Pdcd4: Recent advances in the elucidation of function and regulation. Biol Cell 101: 309-317, 2009.
47. Zhang YY, Chen B and Ding YQ: Metastasis-associated factors facilitating the progression of colorectal cancer. Asian Pac J Cancer Prev 13: 2437-2444, 2012.

48. Yadav L, Puri N, Rastogi V, Satpute P, Ahmad R and Kaur G: Matrix metalloproteinases and cancer - roles in threat and therapy. Asian Pac J Cancer Prev 15: 1085-1091, 2014.

49. Dong CG, Wu WK, Feng SY, Wang XJ, Shao JF and Qiao J: Co-inhibition of microRNA-10b and microRNA-21 exerts synergistic inhibition on the proliferation and invasion of human glioma cells. Int J Oncol 41: 1005-1012, 2012

50. Zhu Q, Wang Z, Hu Y, Li J, Li X, Zhou L and Huang Y: miR-21 promotes migration and invasion by the miR-21-PDCD4-AP-1 feedback loop in human hepatocellular carcinoma. Oncol Rep 27: 1660-1668, 2012.

51. Jiang Y, Zhang SH, Han GQ and Qin CY: Interaction of Pdcd 4 with eIF4E inhibits the metastatic potential of hepatocellular carcinoma. Biomed Pharmacother 64: 424-429, 2010.

52. Khosravi S, Tam KJ, Ardekani GS, Martinka M, McElwee KJ and Ong CJ: eIF4E is an adverse prognostic marker of melanoma patient survival by increasing melanoma cell invasion. J Invest Dermatol 135: 1358-1367, 2015.

53. Ogata-Kawata H, Izumiya M, Kurioka D, Honma Y, Yamada Y, Furuta K, Gunji T, Ohta H, Okamoto H, Sonoda $\mathrm{H}$, et al: Circulating exosomal microRNAs as biomarkers of colon cancer. PLoS One 9: e92921, 2014.

54. Que R, Ding G, Chen J and Cao L: Analysis of serum exosomal microRNAs and clinicopathologic features of patients with pancreatic adenocarcinoma. World J Surg Oncol 11: 219, 2013. 